\title{
Design and Implementation of Adaptive PID and Adaptive Fuzzy Controllers for a Level Process Station
}

\author{
Aparna Venkataraman ${ }^{*}$ \\ Department of Electronics \& Instrumentation Engineering, B. S. Abdur Rahman Crescent Institute of Science \& Technology, \\ Chennai, India
}

Received 11 July 2020; received in revised form 31 October 2020; accepted 20 January 2021

DOI: https://doi.org/10.46604/aiti.2021.6047

\begin{abstract}
This proposed work proposes the design and real-time implementation of an adaptive fuzzy logic controller (FLC) and a proportional-integral-derivative (PID) controller for adaptive gain scheduling that can be configured for any complex industrial nonlinear application. Initially, the open-loop test of the single-input single-output (SISO) system, with nonlinearities and disturbances, is conducted to represent the mathematical model of the process around a set of equilibrium points. The adaptive controllers are then developed and deployed by using the national instruments reconfigurable input/output data acquisition device (NI RIO), NI myRIO-1900, and the control parameters are adapted in real-time corresponding to the changes in the process variable. The resulting servo and regulatory performance of the controllers are compared in MATLAB ${ }^{\circledR}$ software. The adaptive fuzzy controller is deduced to be the better controller as it can generate the desired output with quicker settling times, fewer oscillations, and negligible overshoot.
\end{abstract}

Keywords: adaptive PID, adaptive fuzzy, nonlinear system, level control, data acquisition

\section{Introduction}

The fluid level control is a severe problem in industries as an ineffective control action will cause critical complexities in process operation, which may disagree with the equilibrium of the process reaction. Real-time level control is also a challenging problem because of inherent nonlinear characteristics, such as interaction effects, parametric uncertainties, and input dead time and measurement delays; these nonlinear features significantly affect the accuracy of industrial processes.

Most industrial processes deploy a conventional proportional-integral-derivative (PID) controller for its simple setup. The structure of the PID controller is widespread, and several thumb rules are available to tune its parameters [1-5]. However, in a nonlinear system, a controller built for a specific equilibrium point will not work satisfactorily at other equilibrium points because of system uncertainties resulting from the scaling of the process components. Therefore, a precise control action cannot be achieved with such open-loop PID tuning schemes.

In order to overcome the limitation of the PID controller in a nonlinear plant, gain scheduling is proposed. The scheduling of PID gains is a significant enhancement in the PID structure $[1,6]$ and is usually carried out to reduce the slow convergence of traditional PID controllers. The typical implementation of a PID controller with gain scheduling requires the development of mathematical process models around several equilibrium points and the estimation of corresponding PID gains. Then, the controllers of each operating region would be combined into a single controller for the entire operation region of the plant [7].

* Corresponding author. E-mail address: vaparna06@gmail.com 
However, no algorithms can ascertain the different thumb rules, such as the optimal number of operating points and the appropriate process variable dynamics, to design a gain scheduling PID controller. There is also no practical technique to test the reliability and efficacy of a gain scheduled control system [8-11]. Furthermore, one significant limitation of gain scheduling is its inability to achieve a high precision of stability by minimizing the effects of the external disturbances in the system [12]. Gain scheduled PID is also a model-based design method, and any uncertainty in the process model might have a significant impact on the controller's performance. Hence, it is necessary to use an algorithm with a simple structure that would not require knowledge about the process's mathematical model. Therefore, this continues to be a research interest for various researchers to determine the most accurate and stable control method, which can also reject multiple disturbances.

Even though the gain scheduling PID control produces highly stable and precise control action, its dynamic response is usually inadequate, which leads to overshoot and substantial settling time. Relatively, the fuzzy control logic is capable of excellent dynamic response in nonlinear and time-varying systems by generating outputs with lesser overshoot and response times. Fuzzy logic control (FLC) has rapidly evolved into one of the most successful theories for complex control systems. From control systems to artificial intelligence, fuzzy logic has been applied in many fields.

Fuzzy logic is a suitable alternative to PID structures for nonlinear and time-varying systems [13]. It reduces the oscillations of the manipulated variable around the setpoint, which leads to a quick convergence of the process variable. The most crucial advantage of fuzzy logic is that it does not require knowledge of the mathematical model. Thus, it can effectively handle the parametric uncertainty, which makes it more robust than PID controllers [13-16].

However, for large time-delay systems, a fuzzy logic control scheme might not be considered suitable. It should also be noted that the complex structure of a fuzzy logic controller must be simplified before real-time implementation by combining the proportional error component and its derivative linearly [17-19]. In order to ensure a robust and stable control action, the fuzzy rule base should possess a linear dependence on the summed fuzzy inputs [20].

Since every real-time industrial process is laden with intrinsic nonlinearities, disturbances, process variable saturation, hysteresis, and nonlinear flow dynamics, it is necessary to implement an adaptive controller with high disturbance rejection capability to achieve adequate control against these nonlinearities and time-varying disturbances [21]. In this proposed work, the advantages of both adaptive control and fuzzy logic control were incorporated by implementing an adaptive fuzzy controller, and its efficiency was compared to that of a gain scheduling PID controller.

The various topics of this paper are arranged in the following manner: Section 2 presents a brief description of the various adaptive PID and adaptive fuzzy control techniques employed in complex nonlinear industrial systems. Section 3 details the hardware of the level process station. The mathematical modeling of the process is described in section 4 . The controller design steps and the simulation results are explained in parts 5 and 6. The real-time implementation of the controllers and their corresponding results are presented in section 7. Section 8 discusses the adaptive controllers' performance, and the concluding explanations about the suitable controller for the proposed system are provided in section 9.

\section{Study on Adaptive PID and Adaptive Fuzzy Control Techniques}

Several techniques are proposed in the literature to improve upon the limitations of traditional PID control scheme, namely, adaptive gain scheduling technique, adaptive PID design using the Asynchronous Advantage Actor-Critic (A3C) algorithm, PID control using model reference adaptive control (MRAC) scheme, PID controller tuned with characteristics ratio assignment (CRA) technique, and PID controller with decoupler and inverting decoupler.

The gain scheduling strategy proposed in this work has been successfully implemented in several systems; Sain and Peczkowski [22-24] have implemented gain scheduling PID controllers for engine speed control for several nonlinear turbojet engines. Aparna et al. [25] have successfully designed a gain scheduled multi-loop proportional-integral (PI) level controller 
for a nonlinear interacting multiple-input multiple-output (MIMO) conical tank system. Åstrom [1] has implemented gain scheduling PID control in several systems such as car air-fuel ratio systems, ship steering systems, and effluent systems. Many articles also elaborate on the implementation of fuzzy logic in industrial applications. Zhou et al. [26] implemented an adaptive fuzzy-based PID control scheme to improve the controller's disturbance rejection capability in an inertially stabilized platform (ISP). Cheng et al. [27] developed an FLC scheme to stabilize a double inverted pendulum system.

Mahapatro, Subudhi, and Ghosh proposed the design and implementation of an adaptive fuzzy PI controller [28] and adaptive fuzzy Sliding Mode Controller (SMC) [29] to reduce the chattering and to improve robustness in the liquid level control of a coupled tank system. Tamilselvan and Aarthy [30] proposed an FLC using the Kalman algorithm to control the fluid level in a conical tank system. Sakthivel, Anandhi, and Natarajan [31] designed and implemented a fuzzy logic liquid level controller for a nonlinear spherical tank system with three operating regions.

\section{Process Setup Hardware}

In the level process station, the process tank level is controlled by regulating the fluid's inlet flow rate. A wheel flow meter and an orifice plate with a differential pressure transmitter (DPT) are used to measure the liquid's flow rate in the pipeline. A radio frequency $(\mathrm{RF})$ capacitance level transmitter is used to measure the process tank level.

Initially, a pump with a discharge capacity of $1200 \mathrm{lph}$ is used to fetch the water from the reservoir tank and discharge it to an equal percentage control valve. During the fluid flow through the orifice plate, a differential pressure is developed across it. The DPT, whose corresponding output range is between 4-20 mA, senses the differential pressure. This analog output is converted and scaled to $0-5 \mathrm{~V}$ and fed to the 12-bit analog-to-digital converter (ADC) in national instruments reconfigurable input/output data acquisition device (NI RIO), NI myRIO-1900.

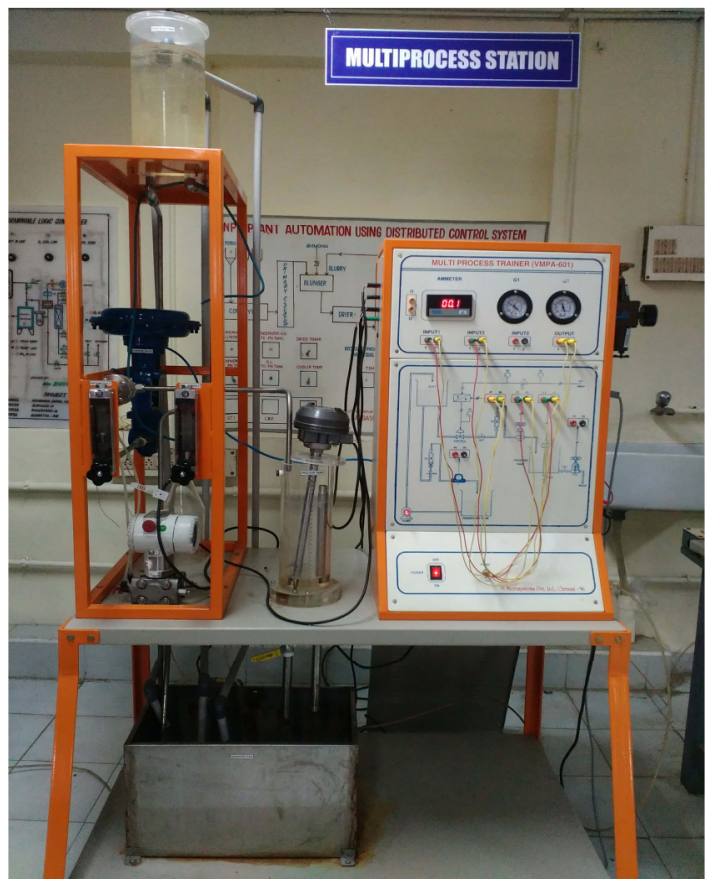

(a) The level process station

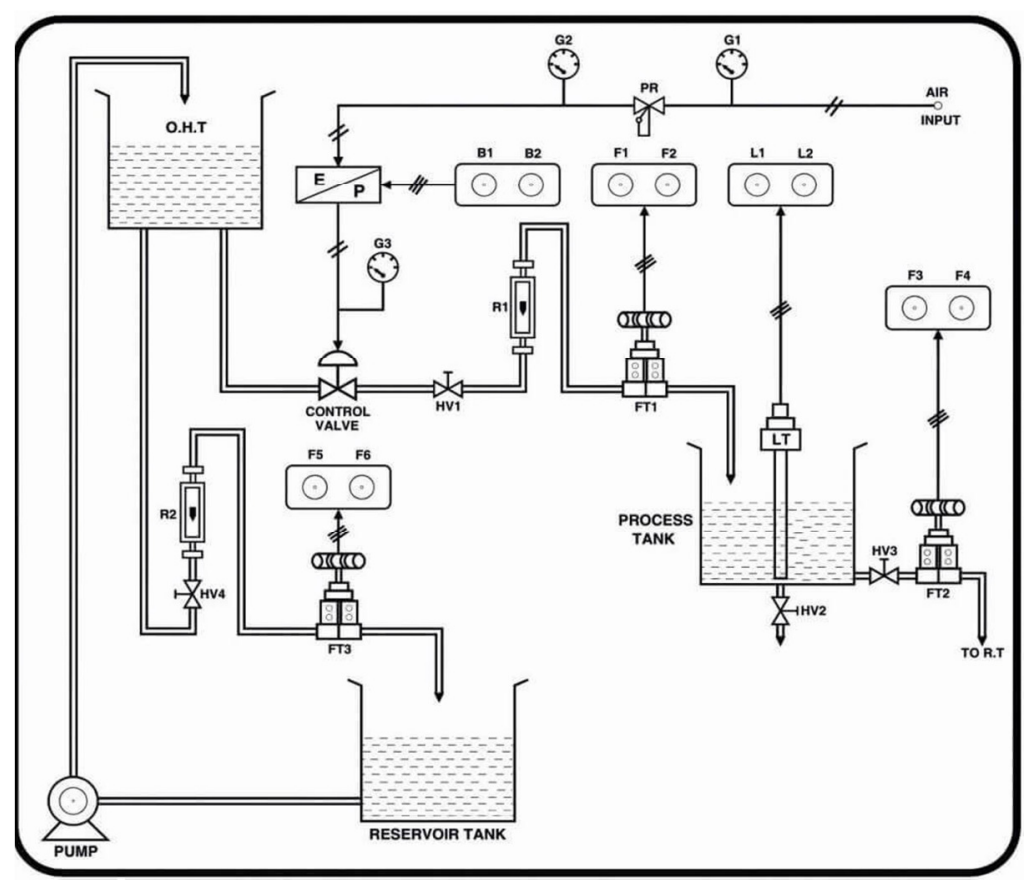

(b) The schematic diagram of the system

Fig. 1 The level process station and its schematic representation

The adaptive PID or adaptive fuzzy control algorithm infers the corresponding digital output, which is later converted to an analog value of $0-5 \mathrm{~V}$ by a 12-bit digital-to-analog converter (DAC). The DAC output is fed to an electro-pneumatic (E/P) converter to generate a 3-15 psi output. The E/P converter's output manipulates the control valve's stem position to regulate the inlet flow rate, which eventually maintains the fluid level at the desired value. Fig. 1 shows the level process station and its schematic diagram on which the adaptive PID and adaptive fuzzy controllers are implemented. 


\section{Mathematical Modeling}

The plant's open-loop response is recorded for different percentages of control valve opening, and the Input/output (I/O) characteristics of the process are plotted. The piecewise linearization of the nonlinear process characteristics yields four operational areas depending on the change in the trajectory's gain. The operating regions' equilibrium points are chosen such that a noticeable difference in the process gain is visualized at each equilibrium point.

The open-loop characteristics are linearized into four operational areas, as depicted in Fig. 2. For each region, the transfer function is derived. The parameters of the transfer function for a first-order system with transportation lag, time constant $(\tau)$, delay time $\left(\mathrm{t}_{\mathrm{d}}\right)$, and process gain $(\mathrm{K})$ are found by using the Cohen-Coon two-point method [32], as shown in Table 1. The system's gain is computed from the slope of the nonlinear regions, and the product between the operating area and the gain yields the time constant. An arbitrary value derived from the test results is chosen as the time delay in the transfer function.

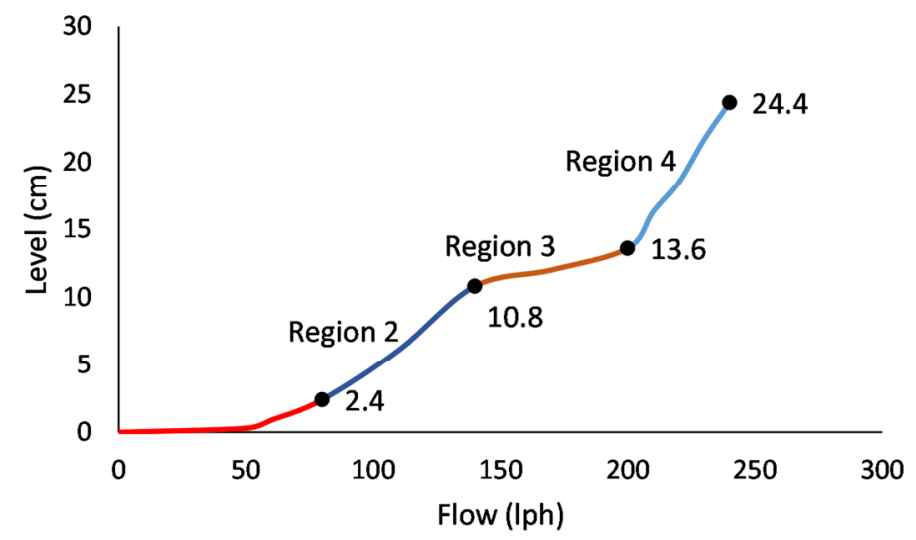

Fig. 2 Linearized I/O response for the level process

Table 1 Transfer function for the various operating regions

\begin{tabular}{|c|c|c|}
\hline Region & Level $(\mathrm{cm})$ & Transfer function \\
\hline 1 & $0-2.4$ & $\frac{1.377}{4.5 s+1} \exp \{-1.5 s\}$ \\
\hline 2 & $2.5-10.8$ & $\frac{1.03}{33 s+1} \exp \{-2 s\}$ \\
\hline 3 & $10.9-13.6$ & $\frac{0.98}{12.75 s+1} \exp \{-2.75 s\}$ \\
\hline 4 & $13.7-24.4$ & $\frac{1}{5.25 s+1} \exp \{-0.95 s\}$ \\
\hline
\end{tabular}

\section{Controller Design}

The design procedure and implementation of the adaptive gain scheduling PID controller and the adaptive fuzzy controller are explained in the following subsections.

\subsection{Design of adaptive gain scheduling PID controller}

Famous and sophisticated Cohen \& Coon tuning rules, (1) to (3), based on the process reaction curve method [32], was used in computing the gains of the adaptive PID controller ( $\mathrm{Kc}, \mathrm{Ki}$, and $\mathrm{Kd}$ ) in each operating zone. The Cohen-Coon tuning method was chosen as it is a reliable and effective technique to generate a quick dynamic response in the proposed self-regulating level process. Table 2 shows the gains computed for the adaptive PID in the various operating regions.

$$
K_{c}=\frac{1}{K}\left(\frac{\tau}{t_{d}}\right)\left[\frac{4}{3}+\frac{1}{4} \frac{t_{d}}{\tau}\right]
$$




$$
\begin{gathered}
T_{i}=t_{d}\left[\frac{32+6\left(\frac{t_{d}}{\tau}\right)}{13+8\left(\frac{t_{d}}{\tau}\right)}\right] * 60 ; K_{i}=\frac{1}{T_{i}} \\
T_{d}=t_{d}\left[\frac{4}{11}+2\left(\frac{t_{d}}{\tau}\right)\right] * 60 ; K_{d}=T_{d}
\end{gathered}
$$

where $\mathrm{K}_{\mathrm{c}}$ is the proportional gain, $\mathrm{T}_{\mathrm{i}}$ is the integral time $(\mathrm{s}), \mathrm{K}_{\mathrm{i}}$ is the integral gain, $\mathrm{T}_{\mathrm{d}}$ is the derivative time (s), and $\mathrm{K}_{\mathrm{d}}$ is the derivative gain.

Table 2 Cohen-Coon PID gains for all the operating regions

\begin{tabular}{|c|c|c|c|}
\hline Region & $\mathrm{K}_{\mathrm{c}}$ & $\mathrm{K}_{\mathrm{i}}$ & $\mathrm{K}_{\mathrm{d}}$ \\
\hline 1 & 1.079 & 9.091 & 0.003 \\
\hline 2 & 5.179 & 6.370 & 0.003 \\
\hline 3 & 4.160 & 3.448 & 0.002 \\
\hline 4 & 2.377 & 4.167 & 0.004 \\
\hline
\end{tabular}

Once the PID controllers were designed for each operating region, the gain scheduling PID controller switched PID gains whenever a setpoint in a particular operating region was provided. This adaptive PID controller adopts online gain change depending on the process operating point and hence possesses better adaptability.

\subsection{Design of adaptive fuzzy controller}

The fuzzy logic control scheme is implemented by using natural language rules and is closer to human thinking than other control logic. Fuzzy logic control can be implemented effectively in five significant steps [33-34]:

(1) Selection of fuzzy inference engine

(2) Design of the fuzzy inference system

(3) Formulation of the fuzzy rule base

(4) Fuzzification

(5) Defuzzification

In the adaptive fuzzy controller design, Mamdani fuzzy inference engine is chosen. A linear combination of error and derivative of the error is given as input to the fuzzy logic controller, and the fluid level is generated as output from the controller. A value of 0 to $100 \%$ is considered for the error and change in error inputs. The minimum and maximum permissible scale of the process variable, ranging from 0 to 25 , is defined for the output. Five membership functions are considered for all the variables, very low value (NB), low value (NS), median value (ME), high value (PS), and very high value (PB).

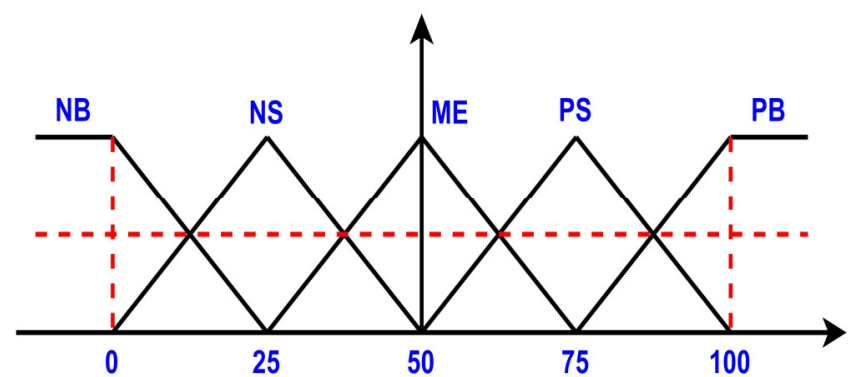

Fig. 3 Range of input membership function in the various operating regions

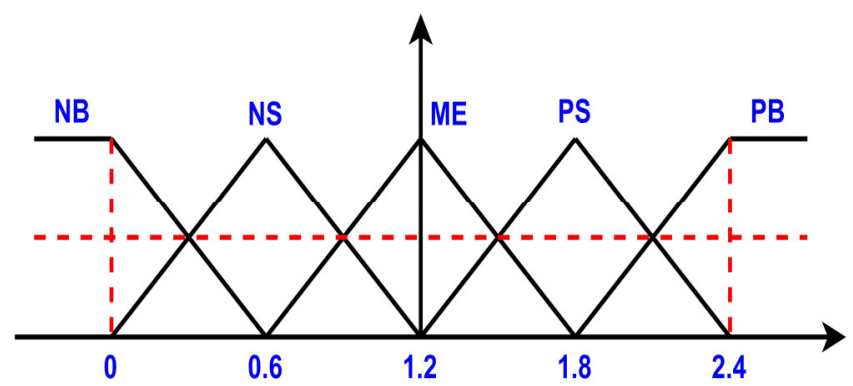

Fig. 4 Range of output membership function in operating region 1 
The following Fig. 3 depicts the input membership functions adopted in all the operating regions, and Fig. 4 illustrates the output membership functions adopted in operating region 1. A combination of several fuzzy membership functions of various shapes and intervals is chosen to narrow down the optimal combination with the lowest mean average percentage error (MAPE). A 5x5 rule base, as given in Table 3, is applied to tune the fuzzy logic controller in each operating region. Minimum implication and centroid defuzzification methods are adopted to generate the crisp output.

Table 3 Fuzzy rule base for the adaptive FLC in operating region 1

\begin{tabular}{|c|c|c|c|c|c|}
\hline error & NB & NS & ME & PS & PB \\
\hline NB & PS & NS & ME & PS & NB \\
\hline NS & ME & PS & NS & NS & PS \\
\hline ME & PB & PB & PB & PB & PB \\
\hline PS & PB & PB & PB & PB & NB \\
\hline PB & PB & NB & NB & PB & NB \\
\hline
\end{tabular}

After membership functions and fuzzy rules are defined for each operating region, the adaptive fuzzy controller switches the fuzzy controller's rules and membership functions whenever a setpoint in a particular operating region is provided, as illustrated in Fig. 5.

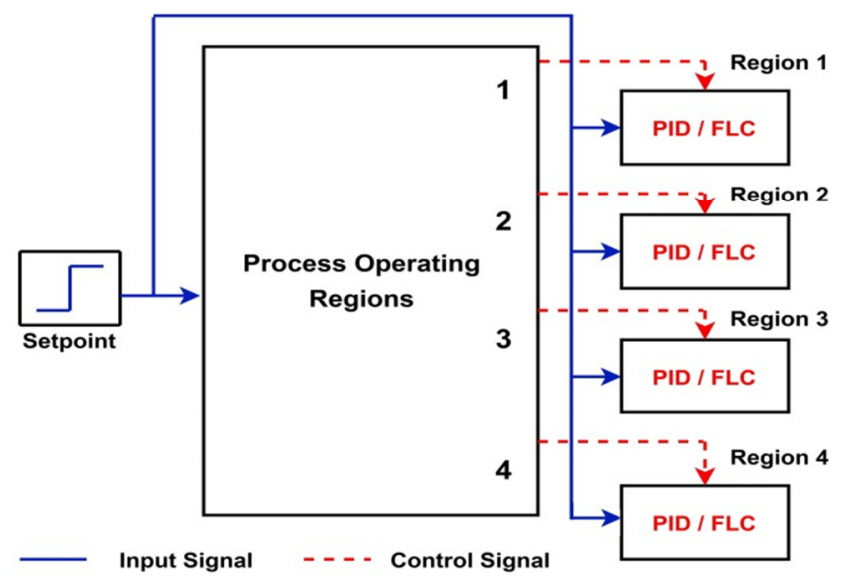

Fig. 5 The schematic diagram of an adaptive gain scheduling PID controller/adaptive FLC

\section{Simulation Results}

Adaptive PID and adaptive fuzzy controllers are designed and tested with input disturbance and different setpoints in various operating regions. The better controller is realized by analyzing the setpoint tracking and input disturbance rejection capability.

The following setpoints are considered that enclosed the entire operating zone of the plant,

Setpoint in operating region $1-$ Level in tank $=2 \mathrm{~cm}$

Setpoint in operating region 2 - Level in tank $=8 \mathrm{~cm}$

Setpoint in operating region $3-$ Level in tank $=12 \mathrm{~cm}$

Setpoint in operating region $4-$ Level in tank $=18 \mathrm{~cm}$

The controllers' response to the simulation tests is described in the following subsections.

\subsection{Servo response}

The setpoint tracking capability of both the adaptive gain scheduling PID controller and the adaptive fuzzy controller is compared for different setpoints in various operating regions. Fig. 6 demonstrates the setpoint tracking capability of the 
adaptive PID controller in the four operating zones. Similarly, Fig. 7 represents the adaptive FLC's servo response in the operating regions 3 and 4 .

From the step-response characteristics of the controllers' servo response presented in Table 4, it can be inferred that the controllers quickly track their setpoints. The servo control action of gain scheduling PID is faster than its counterpart, but it leads to overshoot and oscillations in the response, which is undesirable. With adaptive FLC, its output response reaches a steady state quickly but with a minor steady-state error.

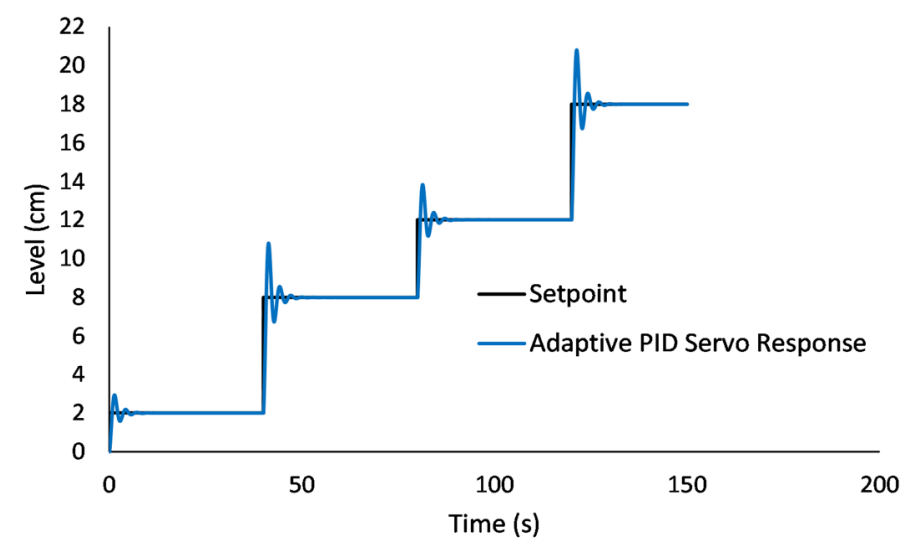

Fig. 6 The servo response of the adaptive PID controller in simulation

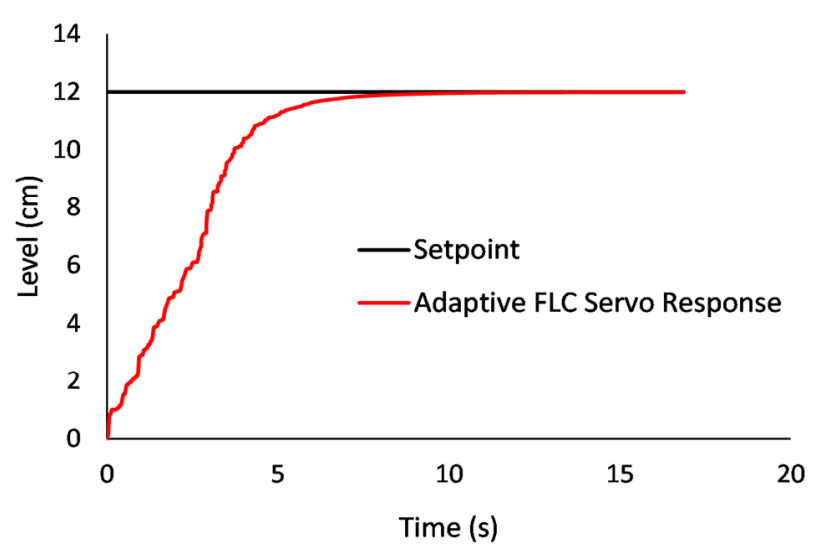

(a) The simulated servo response in region 3

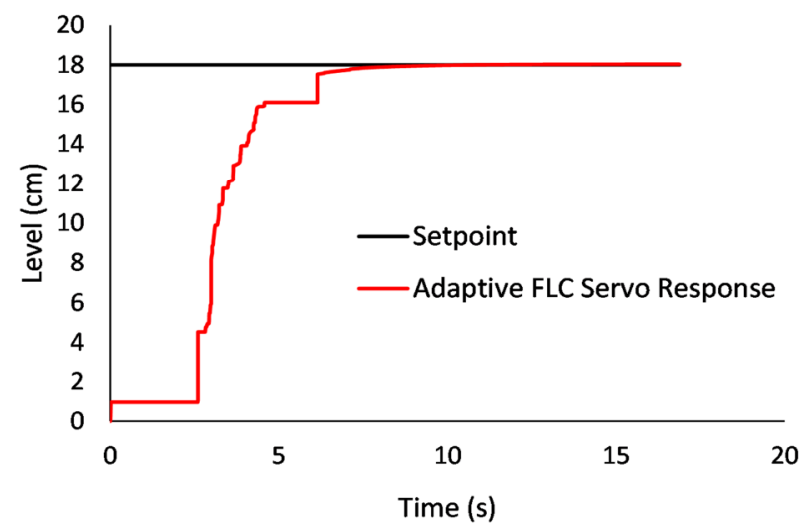

(b) The simulated servo response in region 4

Fig. 7 The servo response of the adaptive FLC in the operating regions $3 \& 4$ in simulation

Table 4 Time-domain specifications of the servo response of the controllers in simulation

\begin{tabular}{|c|c|c|c|c|c|}
\hline Region & Controller & Rise time (s) & Settling time (s) & Overshoot & Offset \\
\hline \multirow{2}{*}{1} & Adaptive gain scheduled PID & 0.508 & 8.105 & 0.444 & - \\
\cline { 2 - 6 } & Adaptive FLC & 4.089 & 7.632 & - & 0.061 \\
\hline \multirow{2}{*}{2} & Adaptive gain scheduled PID & 0.994 & 9.905 & 0.340 & - \\
\cline { 2 - 6 } & Adaptive FLC & 3.895 & 7.073 & - & 0.075 \\
\hline \multirow{2}{*}{3} & Adaptive gain scheduled PID & 1.258 & 8.627 & 0.133 & - \\
\cline { 2 - 6 } & Adaptive FLC & 3.875 & 7.009 & - & 0.010 \\
\hline \multirow{2}{*}{4} & Adaptive gain scheduled PID & 1.509 & 9.306 & 0.151 & - \\
\cline { 2 - 6 } & Adaptive FLC & 1.975 & 6.942 & - & 0.031 \\
\hline
\end{tabular}

\subsection{Servo \& regulatory response}

A disturbance of $+10 \%$ of the setpoint values is applied at $20 \mathrm{~s}, 60 \mathrm{~s}, 100 \mathrm{~s}$, and $120 \mathrm{~s}$ to simulate input disturbance in each operating region so that the servo and regulatory action of the gain scheduling PID controller to a step input and a disturbance can be analyzed simultaneously. Fig. 8 illustrates the servo and regulatory responses of the gain scheduling PID controller subjected to varying setpoints and input disturbance in each operating region. The response within the encircled area in Fig. 8 depicts the regulatory action of the adaptive PID controller. 


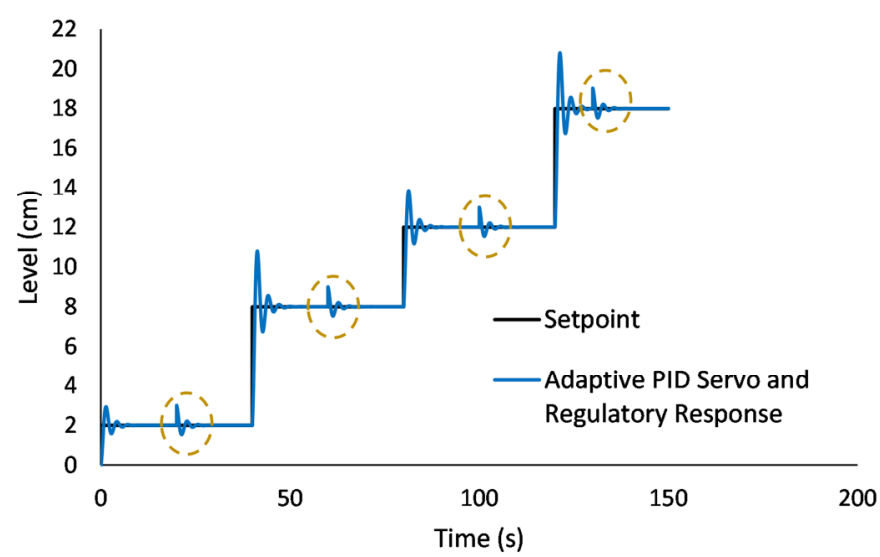

Fig. 8 The servo and regulatory responses of the adaptive PID controller in simulation

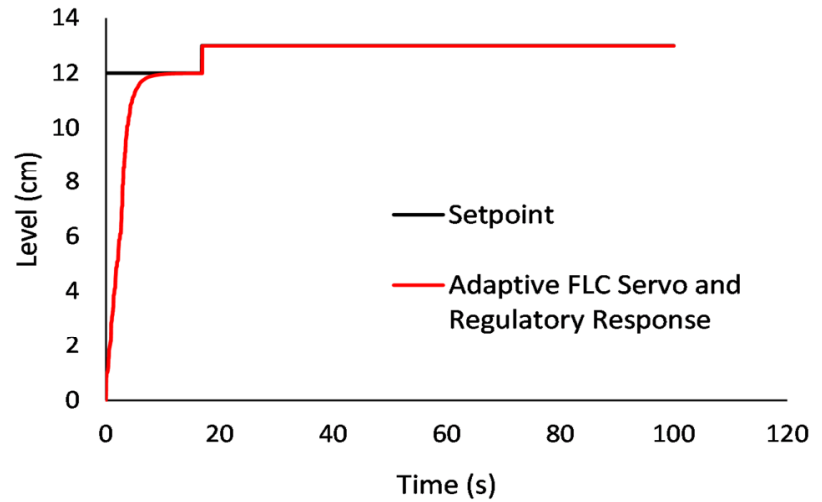

(a) The simulated servo \& regulatory responses in region 3

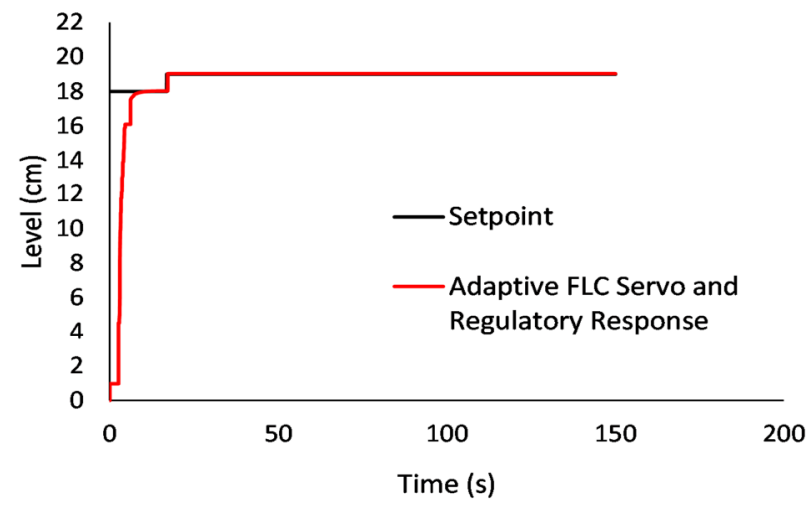

(b) The simulated servo \& regulatory responses in region 4

Fig. 9 The servo and regulatory responses of the adaptive FLC in the operating regions $3 \& 4$ in simulation

Similarly, the setpoint tracking capability and the disturbance rejection capability of the adaptive fuzzy controller are tested by applying varying setpoints and a step input change of ' 1 ' at $20 \mathrm{~s}$ in each operating region. The corresponding result in Fig. 9 shows the servo and regulatory control action of the adaptive fuzzy controller in the operating regions 3 and 4 .

It can be seen from Figs. 8, Figs. 9, and the time-domain specifications of the servo and regulatory responses described in Table 5 that the controllers exhibit similar behavior as with their servo control loop. The adaptive PID is capable of quicker control action with overshoot, and the adaptive FLC is the fastest to reject the disturbance and track the setpoint with a small offset.

Table 5 The time-domain specifications of the servo and regulatory responses of the controllers in simulation

\begin{tabular}{|c|c|c|c|c|c|}
\hline Region & Controller & Rise time (s) & Settling time (s) & Overshoot & Offset \\
\hline \multirow{2}{*}{1} & Adaptive gain scheduled PID & 0.508 & 7.125 & 0.444 & - \\
\cline { 2 - 6 } & Adaptive FLC & 4.089 & 1.431 & - & 0.061 \\
\hline \multirow{2}{*}{2} & Adaptive gain scheduled PID & 0.994 & 6.179 & 0.340 & - \\
\cline { 2 - 6 } & Adaptive FLC & 3.895 & 0.869 & - & 0.075 \\
\hline \multirow{2}{*}{3} & Adaptive gain scheduled PID & 1.258 & 5.985 & 0.133 & - \\
\cline { 2 - 6 } & Adaptive FLC & 3.875 & 0.234 & - & 0.009 \\
\hline \multirow{2}{*}{4} & Adaptive gain scheduled PID & 1.509 & 6.805 & 0.151 & - \\
\cline { 2 - 6 } & Adaptive FLC & 1.975 & 1.717 & - & 0.031 \\
\hline
\end{tabular}

\section{Real-Time Implementation \& Results}

The adaptive PID and adaptive fuzzy controller designed in the simulation are implemented in real-time using NI myRIO-1900 reconfigurable I/O data acquisition device that comprises Xilinx processor and supports real-time programming to generate quicker response times in applications. Fig. 10 depicts the schematic diagram for the real-time implementation of the adaptive control loop. Fig. 11 illustrates the wiring diagram to connect the NI myRIO-1900 with the level process station. 
In the proposed system, the DPT's output is converted and scaled to 0-5 V and fed to the differential analog inputs (AI+ and AI-) of the 12-bit ADC in NI myRIO-1900. The data from NI myRIO are scaled to the operating range of fluid level and fed to the adaptive PID and adaptive fuzzy control loop developed in LabVIEW software, as shown in Figs. 12 and 13 , respectively. The configurations of the offline controllers are assumed for the real-time implementation, and the adaptive controllers are configured in the front panel and block diagram of the LabVIEW software.

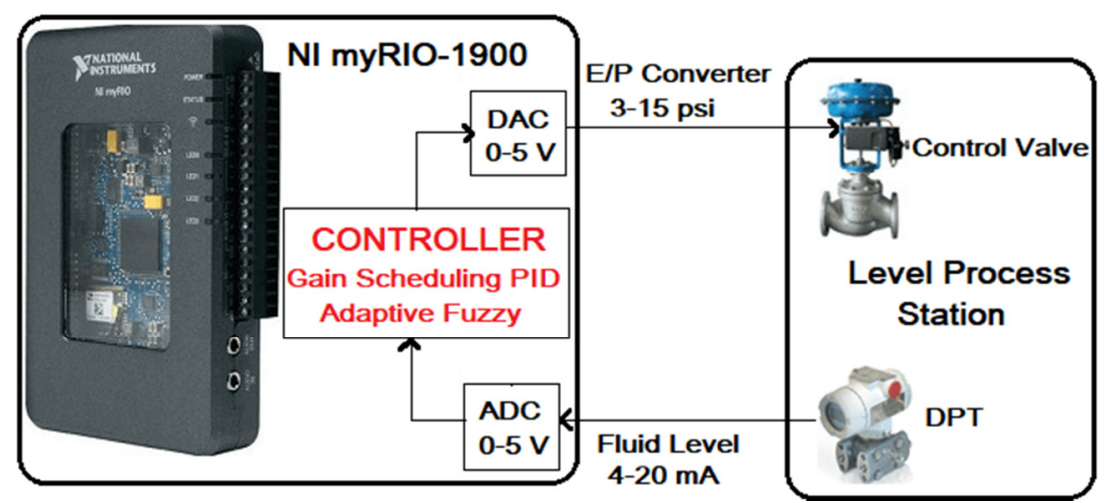

Fig. 10 The schematic diagram for the real-time implementation of the adaptive control loop in the plant

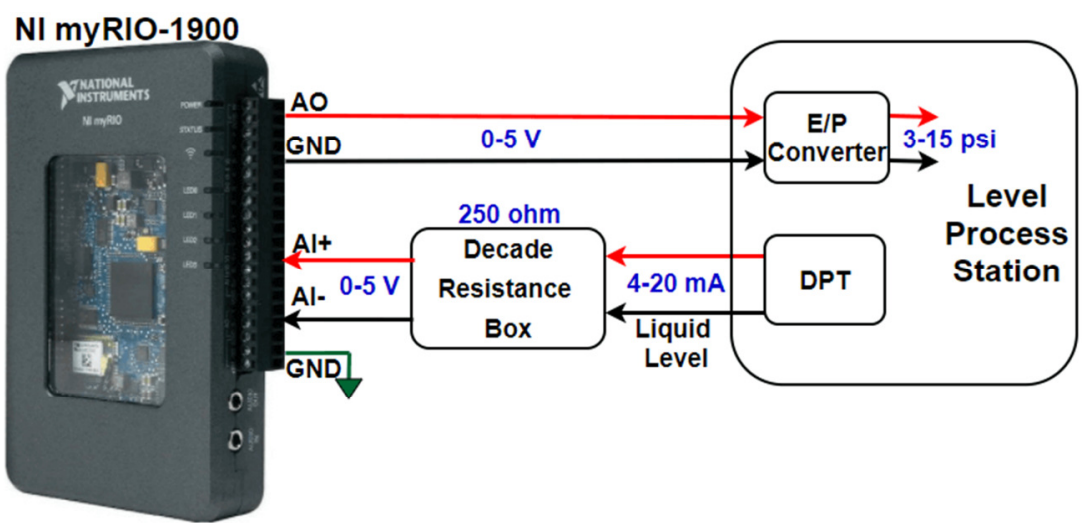

Fig. 11 The wiring diagram to connect the NI myRIO-1900 with the level process station

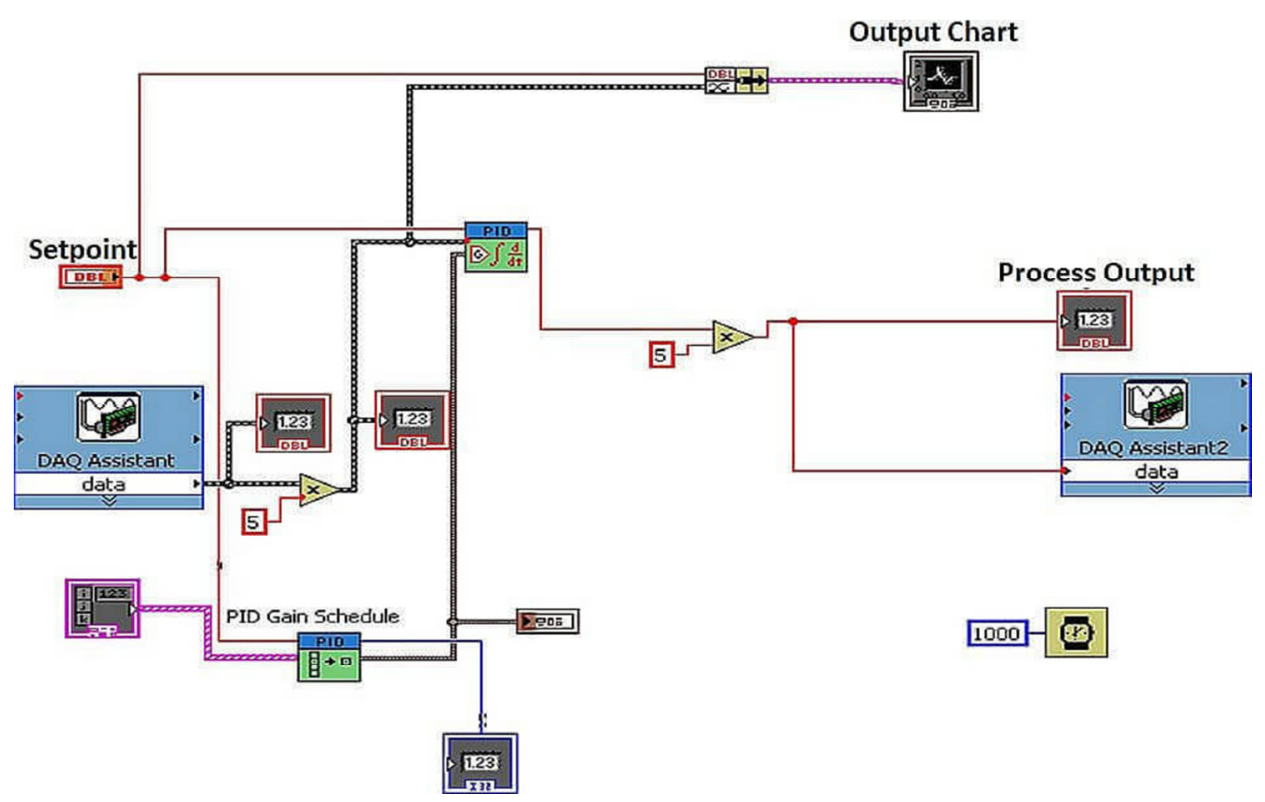

Fig. 12 The block diagram of the adaptive gain scheduling PID control loop in LabVIEW

When the desired setpoint is provided, the controller configurations are switched to the specific operating conditions, and the corresponding level output is obtained. This level output is then scaled to an analog value of 0-5 V by a 12-bit DAC before it is fed to the analog output channel (AO) of NI myRIO-1900. The output voltage is provided to an E/P converter whose output regulated the control valve's stem position to maintain the fluid level of the process tank at the desired value. 


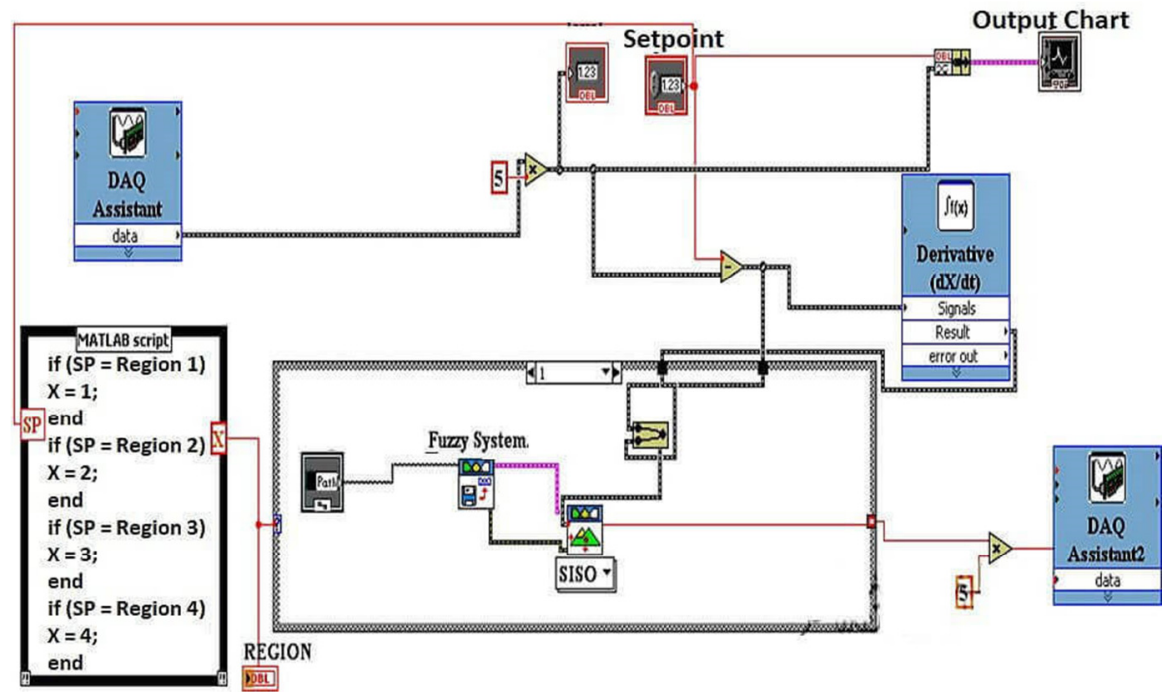

Fig. 13 The block diagram of the adaptive FLC loop in LabVIEW

The experiments are conducted with similar setpoints in the simulation to study the efficacy of adaptive PID and adaptive fuzzy controller in the process plant. The servo and regulatory capability of the adaptive controllers in the real-time plant are discussed in the following subsections.

\subsection{Setpoint tracking capability}

The servo capability of the controllers is tested by providing setpoints in different operating regions. A different setpoint value is provided for every $150 \mathrm{~s}$ to analyze the servo behavior of the adaptive gain scheduling PID controller. Similarly, the adaptive FLC's servo control capability is tested by providing different setpoints for every $300 \mathrm{~s}$. Fig. 14 depicts the resulting servo response of the adaptive PID controller in the four operating regions, and Fig. 15 portrays the servo response of adaptive FLC in operating regions 3 and 4.

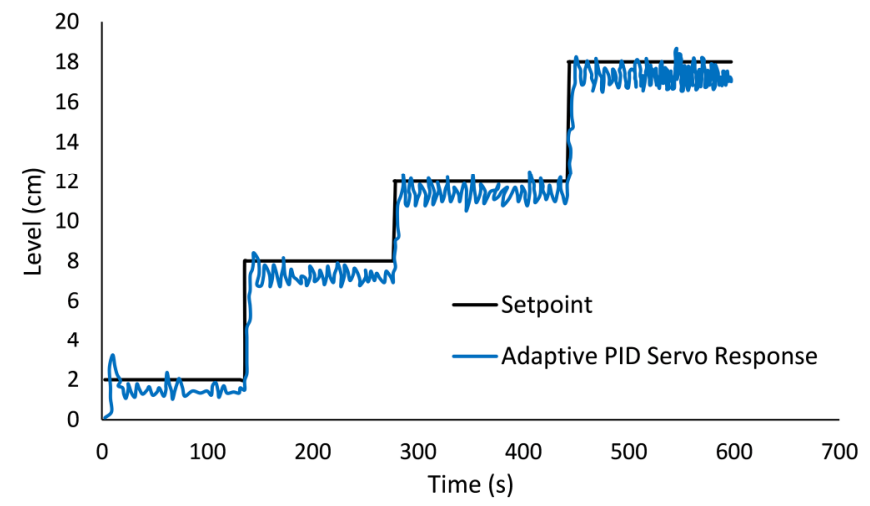

Fig. 14 The servo response of the adaptive PID controller using NI myRIO-1900

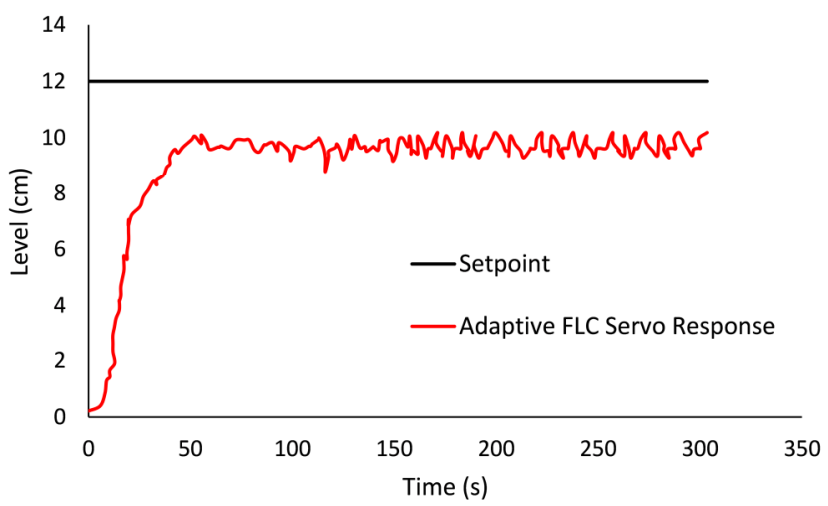

(a) The real-time servo response in region 3

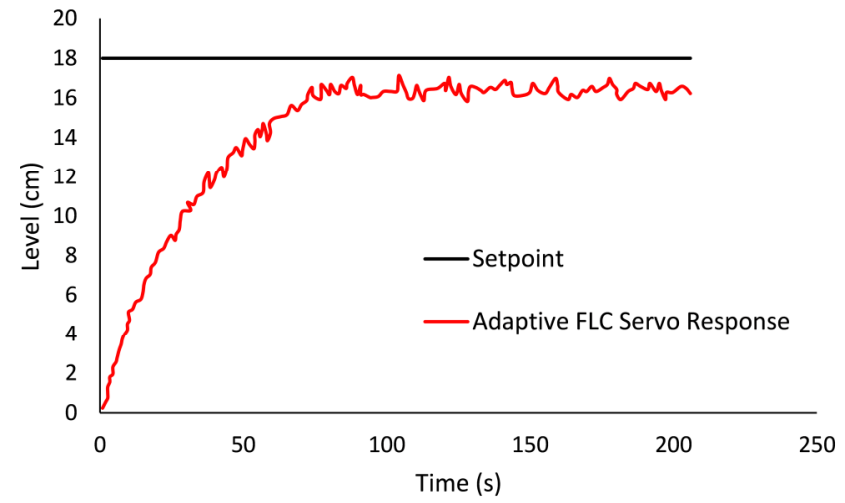

(b) The real-time servo response in region 4

Fig. 15 The servo response of the adaptive FLC in the operating regions $3 \& 4$ using NI myRIO-1900 
The servo response of the controllers can be inferred from the step-response characteristics given in Table 6. The adaptive PID can generate a quicker response with significant overshoot, oscillations, and offset. In contrast, the adaptive FLC can quickly attain a steady state with no overshoot but with a significant steady-state error.

Table 6 The time-domain specifications of the servo response of the controllers in real-time plant

\begin{tabular}{|c|c|c|c|c|c|}
\hline Region & Controller & $\begin{array}{c}\text { Rise time (s) } \\
\text { (approx.) }\end{array}$ & $\begin{array}{c}\text { Settling time } \\
\text { (s) (approx.) }\end{array}$ & $\begin{array}{c}\text { Overshoot } \\
\text { (approx.) }\end{array}$ & $\begin{array}{c}\text { Offset } \\
\text { (approx.) }\end{array}$ \\
\hline \multirow{2}{*}{1} & $\begin{array}{c}\text { Adaptive gain } \\
\text { scheduled PID }\end{array}$ & 4.145 & 25.746 & 1.648 & 1.769 \\
\cline { 2 - 6 } & Adaptive FLC & 18.963 & 22.011 & - & 1.998 \\
\hline \multirow{2}{*}{2} & $\begin{array}{c}\text { Adaptive gain } \\
\text { scheduled PID }\end{array}$ & 6.470 & 39.614 & 1.010 & 1.572 \\
\cline { 2 - 7 } & Adaptive FLC & 27.322 & 34.785 & - & 1.627 \\
\hline \multirow{2}{*}{3} & $\begin{array}{c}\text { Adaptive gain } \\
\text { scheduled PID }\end{array}$ & 9.196 & 63.416 & 0.068 & 1.477 \\
\cline { 2 - 7 } & Adaptive FLC & 43.198 & 55.303 & - & 1.817 \\
\hline \multirow{2}{*}{4} & $\begin{array}{c}\text { Adaptive gain } \\
\text { scheduled PID }\end{array}$ & 12.649 & 106.794 & 0.022 & 0.600 \\
\cline { 2 - 7 } & Adaptive FLC & 69.027 & 91.976 & - & 0.973 \\
\hline
\end{tabular}

\subsection{Setpoint tracking \& input disturbance rejection capabilities}

The adaptive controllers' servo and regulatory responses are tested by changing the setpoint and the inlet hand valve position for $20 \mathrm{~s}$. Besides the inherent disturbances in a real-time plant, this change in the inlet hand valve's position for a specific period mimics input disturbance as the intrinsic characteristics of an equal percentage control valve are not matched to the process's flow conditions in an industrial setup. Therefore, the steady-state flow rate corresponding to the controller output is not linear, and this behavior is used in the analysis of the servo and regulatory responses of the controllers.

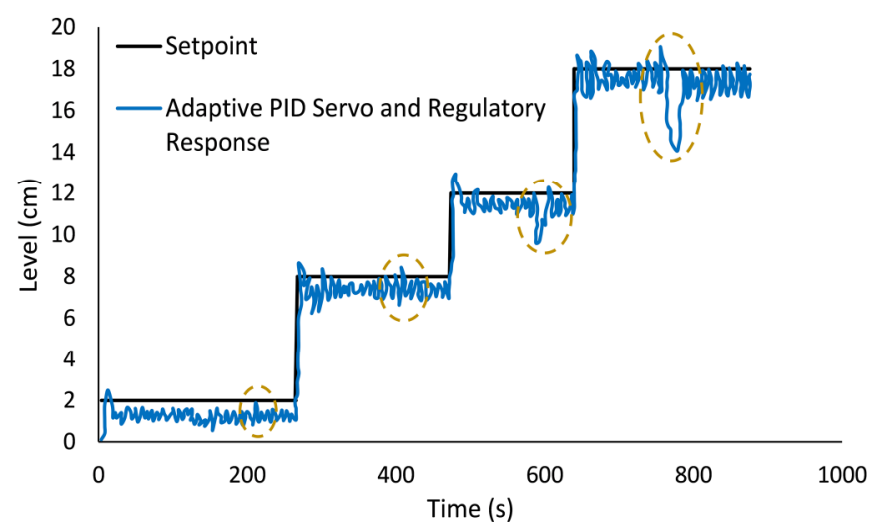

Fig. 16 The servo and regulatory responses of the adaptive PID controller using NI myRIO-1900

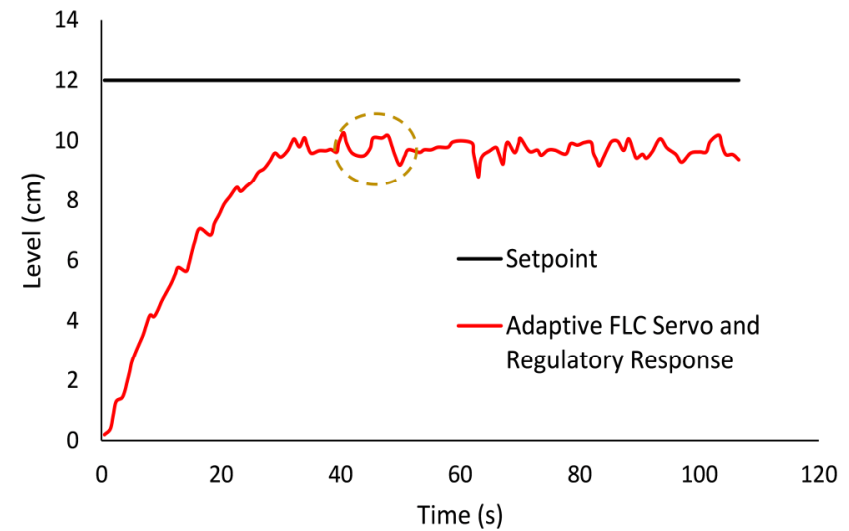

(a) The real-time servo \& regulatory responses in region 3

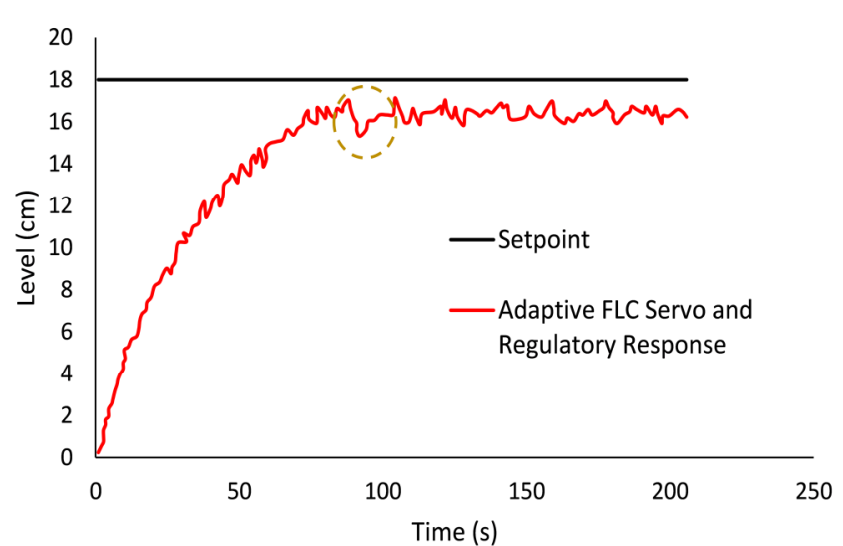

(b) The real-time servo \& regulatory responses in region 4

Fig. 17 Servo and regulatory responses of the adaptive FLC in the operating regions $3 \& 4$ using NI myRIO-1900 
Fig. 16 illustrates the servo and regulatory responses of the adaptive PID controller to varying setpoints and input disturbance in the four operating regions. Fig. 17 presents the servo and regulatory responses of the adaptive fuzzy controller in operating regions 3 and 4, and the response within the encircled area in Figs. 16 and 17 depicts the controllers' regulatory action.

From the responses depicted in Figs. 16, Figs. 17, and the time-domain specifications of the servo and regulatory responses stated in Table 7; it can be inferred that the controllers are capable of effective disturbance rejection and setpoint tracking. Although the adaptive PID controller exhibits quicker control action, it generates significant overshoot, oscillations, and offset in the response. In contrast, the adaptive FLC displays better regulatory capabilities than its counterpart by generating steady-state output quickly with no overshoot but with a significant offset.

Table 7 Time-domain specifications of the servo and regulatory responses of the controllers in real-time plant

\begin{tabular}{|c|c|c|c|c|c|}
\hline Region & Controller & $\begin{array}{c}\text { Rise time (s) } \\
\text { (approx.) }\end{array}$ & $\begin{array}{c}\text { Settling time } \\
\text { (s) (approx.) }\end{array}$ & $\begin{array}{c}\text { Overshoot } \\
\text { (approx.) }\end{array}$ & $\begin{array}{c}\text { Offset } \\
\text { (approx.) }\end{array}$ \\
\hline \multirow{2}{*}{1} & $\begin{array}{c}\text { Adaptive gain } \\
\text { scheduled PID }\end{array}$ & 4.145 & 29.211 & 1.648 & 1.769 \\
\cline { 2 - 6 } & Adaptive FLC & 18.963 & 19.030 & - & 1.997 \\
\hline \multirow{2}{*}{2} & $\begin{array}{c}\text { Adaptive gain } \\
\text { scheduled PID }\end{array}$ & 6.470 & 24.233 & 1.010 & 1.572 \\
\cline { 2 - 7 } & Adaptive FLC & 27.322 & 12.561 & - & 1.627 \\
\hline \multirow{2}{*}{3} & $\begin{array}{c}\text { Adaptive gain } \\
\text { scheduled PID }\end{array}$ & 9.196 & 29.970 & 0.068 & 1.478 \\
\cline { 2 - 7 } & Adaptive FLC & 43.198 & 13.154 & - & 1.817 \\
\hline \multirow{2}{*}{4} & $\begin{array}{c}\text { Adaptive gain } \\
\text { scheduled PID }\end{array}$ & 12.649 & 26.983 & 0.022 & 0.598 \\
\cline { 2 - 7 } & Adaptive FLC & 69.027 & 18.431 & - & 0.972 \\
\hline
\end{tabular}

\section{Discussions}

The setpoint tracking and the disturbance rejection capability of the simulated controllers and the real-time controllers are compared and depicted in Figs. 18 to 21. The servo response of the controllers in the simulation in the operating regions 3 and 4 is compared in Fig. 18. Similarly, the servo and regulatory responses of the controllers in the simulation in the operating regions 3 and 4 are compared and depicted in Fig. 19, wherein the response within the encircled area illustrates the adaptive controllers' regulatory action.

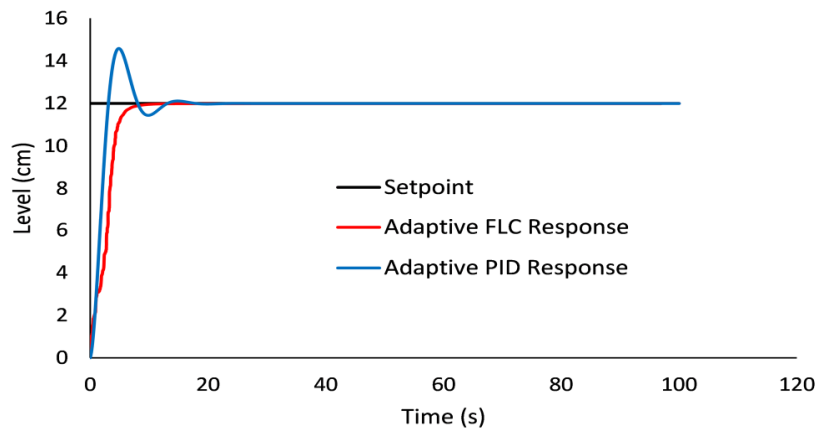

(a) The simulated servo responses in region 3

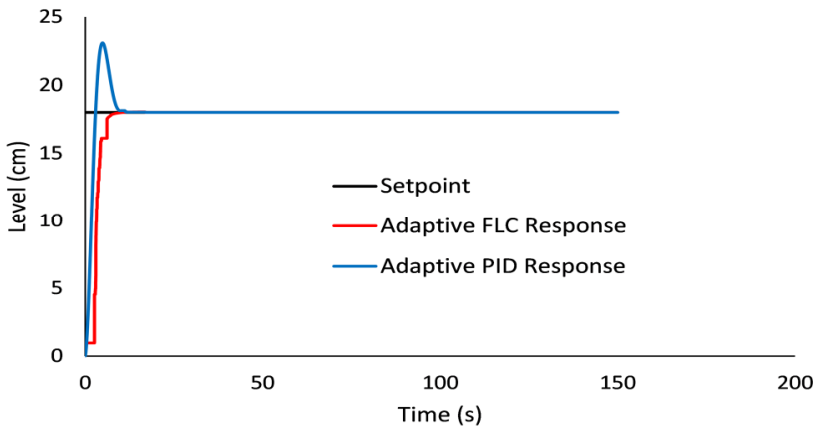

(b) The simulated servo responses in region 4

Fig. 18 The comparison of servo response of the controllers in the operating regions $3 \& 4$ in simulation

Although the adaptive PID controller responds quickly to variations in the process variable, the response is rather abrupt, leading to overshoots and sharp oscillations. Meanwhile, the response of the adaptive fuzzy controller is smooth without fluctuations. Further, Fig. 20 demonstrates the servo behavior of the proposed controllers in the operating regions $3 \& 4$ in the process plant. Fig. 21 shows the servo and regulatory behavior of the adaptive controllers in real-time in the operating regions $3 \& 4$, wherein the response within the encircled area depicts the controllers' regulatory action. 


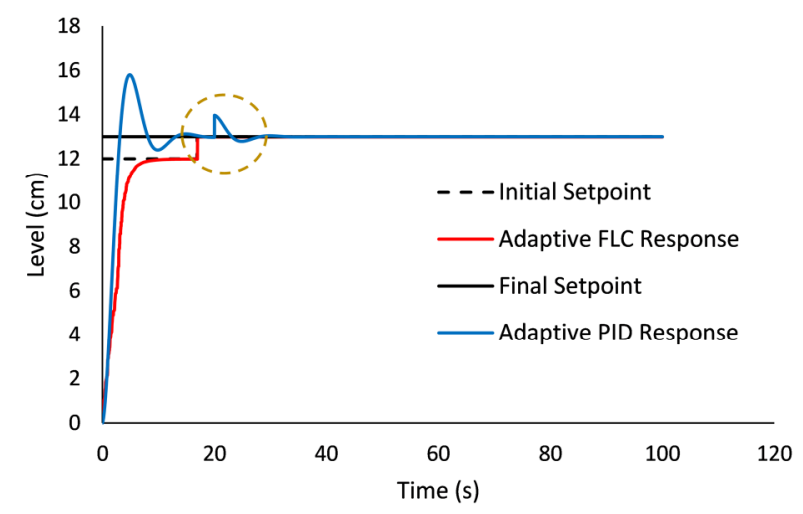

(a) The simulated servo \& regulatory responses in region 3

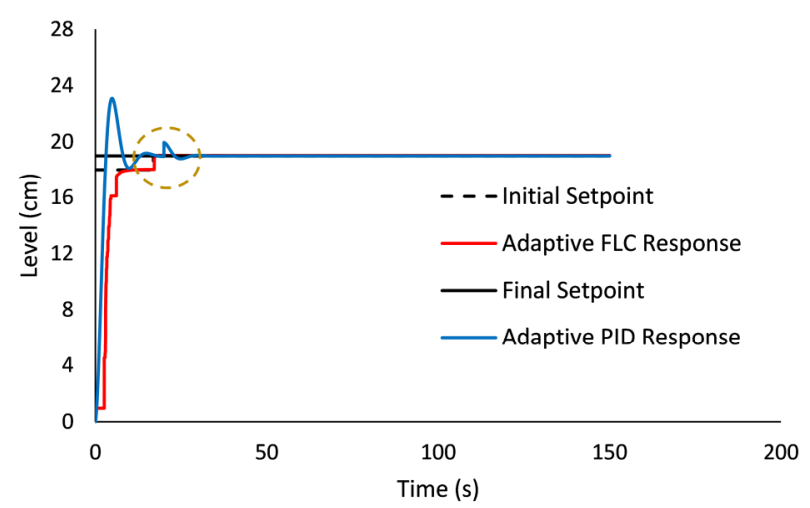

(b) The simulated servo \& regulatory responses in region 4

Fig. 19 The comparison of servo and regulatory responses of the controllers in the operating regions 3 \& 4 in simulation

From the responses illustrated in Fig. 20, Fig. 21, and the time-domain specifications stated in Table 8, it can be visualized that a large offset is generated by both the controllers in the real-time plant, even if the adaptive PID controller generates virtually no offset in simulation. Hence, even though the adaptive PID exhibits excellent steady-state behavior in the simulation, both the controllers generate a residual steady-state error, which leads to poor steady-state behavior in the real-time plant.

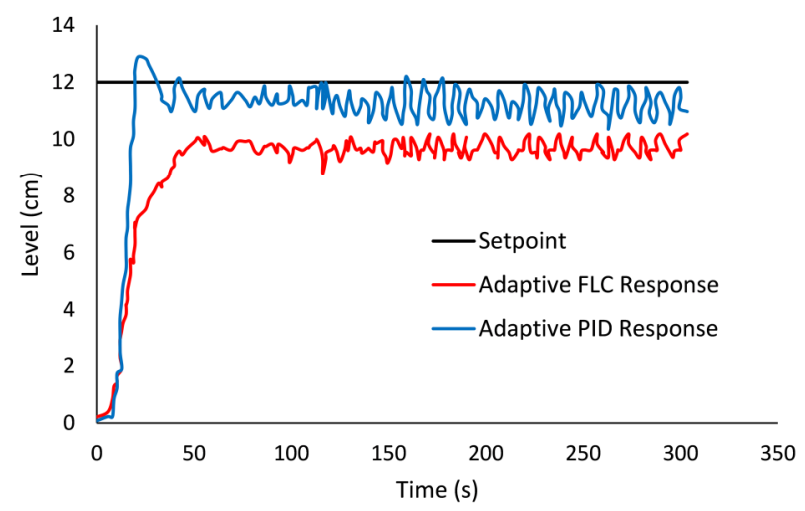

(a) The real-time servo responses in region 3

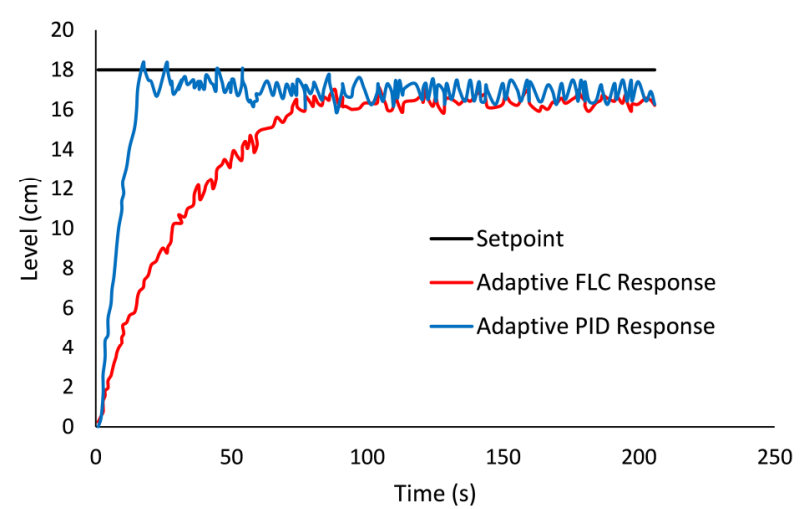

(b) The real-time servo responses in region 4

Fig. 20 The comparison of servo response of the controllers in the operating regions $3 \& 4$ using NI myRIO-1900

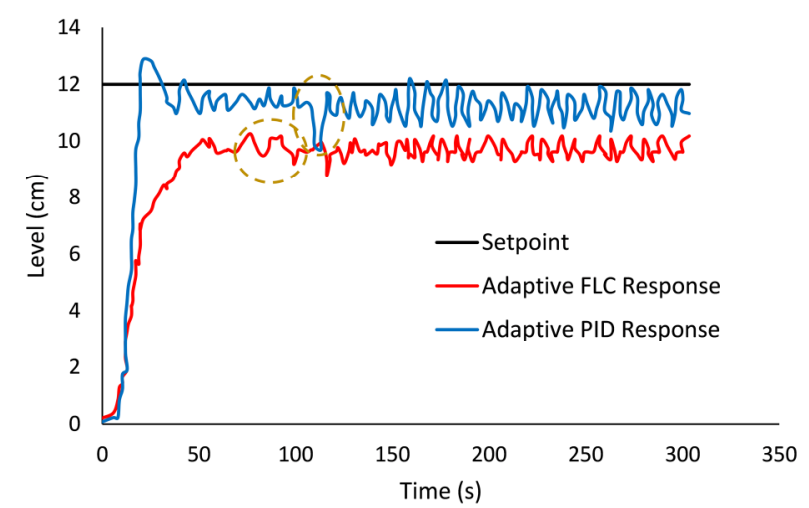

(a) The real-time servo \& regulatory responses in region 3

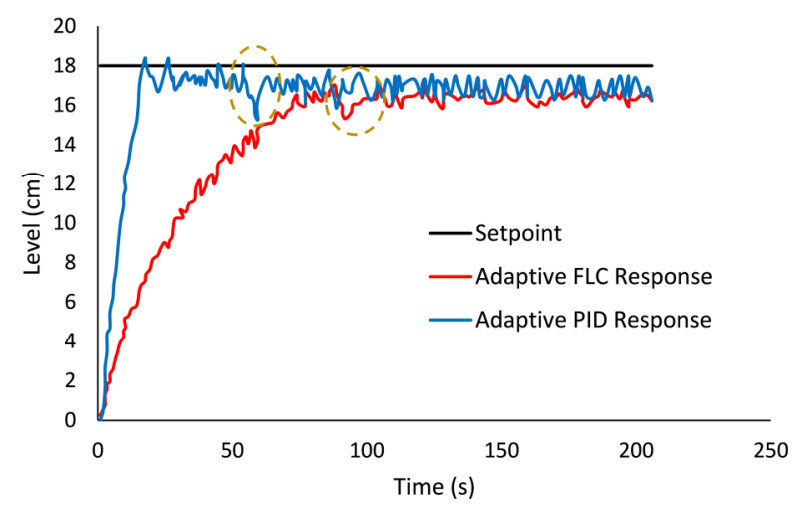

(b) The real-time servo \& regulatory responses in region 4

Fig. 21 The comparison of servo and regulatory responses of the controllers in the operating regions $3 \& 4$ using NI myRIO-1900

The adaptive PID controller's dynamic property is also weak, even if the control action is highly stable in the process plant. Meanwhile, the adaptive fuzzy controller exhibits excellent dynamic control capability with reduced settling times, overshoot, and oscillations in the presence of disturbances. However, one major disadvantage of the adaptive fuzzy controller is that expert knowledge is necessary to configure the controller for variations of process variables, unlike in adaptive PID, where changes require no estimation or computation as the controller is tuned for each change beforehand. 
Nonetheless, the adaptive fuzzy controller is preferable in the proposed real-time plant than its counterpart as the fuzzy logic algorithm does not rely on the mathematical model but the dynamics of the process. Thus, the adaptive FLC designed with adequate knowledge of the process dynamics helps generate the desired output response with less overshoot and oscillations despite inherent model uncertainties, disturbances, and nonlinearities.

Table 8 The comparison of the response of the controllers in simulation and real-time plant

\begin{tabular}{|c|c|c|c|c|}
\hline $\begin{array}{c}\text { Servo \& } \\
\text { Regulatory } \\
\text { response }\end{array}$ & $\begin{array}{c}|c| \\
\text { Simulation } \\
\text { scheduled PID } \\
\text { controller }\end{array}$ & $\begin{array}{c}\text { Adaptive } \\
\text { FLC }\end{array}$ & $\begin{array}{c}\text { Adaptive gain } \\
\text { scheduled PID } \\
\text { controller }\end{array}$ & $\begin{array}{c}\text { Adaptive } \\
\text { FLC }\end{array}$ \\
\hline Rise time & Quick & Slow & Quick & Slow \\
\hline Settling time & Slow & Quick & Slow & Quick \\
\hline Overshoot & More & No & Slightly More & No \\
\hline Offset & No & Negligible & Significant & Significant \\
\hline
\end{tabular}

\section{Conclusions}

In this proposed work, a single-input single-output (SISO) system was modeled around a set of operating points because of system nonlinearities resulting from the inherent hysteresis of components, model uncertainties, and other disturbances. An adaptive gain scheduling PID controller and an adaptive fuzzy controller were then designed and simulated for the modeled system. The configurations and tuning parameters of the simulated controllers were used to implement the controllers in real-time using the NI myRIO-1900 data acquisition device. The efficacy of the controllers in real-time experiments was studied by analyzing their servo and regulatory responses. Both the adaptive controllers showed poor steady-state behavior in the face of uncertainties and disturbances.

Meanwhile, the adaptive fuzzy controller's dynamic control behavior was marginally superior to its counterpart with reduced settling times and overshoot. Therefore, it was concluded from the adaptive controllers' response that the adaptive FLC is better suited to generate the desired output from the proposed real-time plant with quicker settling times and negligible overshoot than the adaptive PID controller despite the adaptive FLC's insufficient steady-state control action.

The author aims to reduce the residual steady-state error of the controllers in future works by adopting advanced meta-heuristic optimization algorithms and robust algorithms to tune the gain scheduling PID controller. Similarly, incorporating a self-tuning logic in the adaptive fuzzy controller would drastically improve the steady-state control action in future research works, owing to the automatic generation of rules based on the initial pre-defined conditions, process trends, and the adaptation law.

\section{Acknowledgement}

The author is very grateful to Dr. U. Sabura Banu, Professor at B. S. Abdur Rahman Crescent Institute of Science and Technology, for her insightful ideas.

\section{Abbreviations}

\begin{tabular}{|l|l|}
\hline A3C & Asynchronous Advantage Actor-Critic \\
\hline ADC & Analog-to-Digital Converter \\
\hline AI & Analog Input \\
\hline AO & Analog Output \\
\hline CRA & Characteristics Ratio Assignment \\
\hline DPT & Differential Pressure Transmitter \\
\hline DAC & Digital-to-Analog Converter \\
\hline E/P & Electro-Pneumatic \\
\hline
\end{tabular}




\begin{tabular}{|l|l|}
\hline FLC & Fuzzy Logic Control \\
\hline I/O & Input/Output \\
\hline ISP & Inertially Stabilized Platform \\
\hline MAPE & Mean Average Percentage Error \\
\hline MIMO & Multiple-Input Multiple-Output \\
\hline MRAC & Model Reference Adaptive Control \\
\hline NI RIO & National Instruments Reconfigurable Input/Output \\
\hline PI & Proportional-Integral \\
\hline PID & Proportional-Integral-Derivative \\
\hline RF & Radio Frequency \\
\hline SISO & Single-Input Single-Output \\
\hline SMC & Sliding Mode Controller \\
\hline
\end{tabular}

\section{Conflicts of Interest}

The authors declare no conflict of interest.

\section{References}

[1] K. J. Åström, Adaptive Control, Dover Books on Electrical Engineering, $2^{\text {nd }}$ ed. Berlin: Heidelberg, 1991.

[2] T. Hagiwara, I. Murakami, T. Sakanushi, K. Yamada, and Y. Ando, A Design Method of Robust Stabilizing Modified PID Conterollers for Multiple-InputMultiple-Output Plants, vol. 5. Three Park Avenue, New York, NY 10016-5990: ASME, 2009.

[3] K. J. Åström and R. M. Murray, Feedback Systems: An Introduction for Scientists and Engineers, Princeton University Press, 2008.

[4] K. H Ang, G. Chong, and L. Yun, "PID Control System Analysis, Design, and Technology," IEEE Transactions on Control Systems Technology, vol. 13, no. 4, pp. 559-576, July 2005.

[5] K. J. Åström and T. Hägglund, “The Future of PID Control,” Control Engineering Practice, vol. 9, no. 11, pp. 1163-1175, November 2001.

[6] G. Stein, Adaptive Flight Control, Connecticut: Yale University, 1980.

[7] W. J. Rugh and J. S. Shamma, "Research on Gain Scheduling," Automatica, vol. 36, no. 10, pp. 1401-1425, October 2000.

[8] J. S. Shamma, "Analysis and Design of Gain Scheduled Control Systems," Department of Mechanical Engineering, Massachusetts Institute of Technology, Technical Report LIDS-TH-1770, May 1988.

[9] J. S. Shamma and M. Athans, "Guaranteed Properties of Gain Scheduled Control for Linear Parameter-Varying Plants," Automatica, vol. 27, no. 3, pp. 559-564, May 1991.

[10] W. J. Rugh, “Analytical Framework for Gain Scheduling,” American Control Conference, May 1990.

[11] M. Sain and S. Yurkovich, "Controller Scheduling: A Possible Algebraic Viewpoint," American Control Conference, June 1982.

[12] M. K. Masten, "Inertially Stabilized Platforms for Optical Imaging Systems," IEEE Control Systems Magazine, vol. 28, no. 1, February 2008.

[13] Z. Yu, J. Z. Cao, H. T. Yang, H. N. Guo, B. Gao, and L. Yang, “Advanced Fuzzy PID Composite Control for Stabilized Platform System,” 2012 IEEE International Conference on Mechatronics and Automation, August 2012.

[14] A. A. Roshdy, Y. Z. Lin, C. Su, H. F. Mokbel, and T. Wang, "Design and Performance of Nonlinear Fuzzy Logic PI Controller for Line of Sight Stabilized Platform," International Conference on Optoelectronics and Microelectronics, August 2012.

[15] M. Yang, X. H. Gao, X. J. Zhang, and C. Wang, "Simulation Analysis of Multi-Axle Vehicle's Turning Braking Stability Based on Fuzzy Control Theory," The 2nd International Conference on Industrial Mechatronics and Automation, May 2010.

[16] H. Zhou, W. Chen, and K. Fang, "A Fuzzy Control Algorithm for Collecting Main Pressure Controlling Using Expert Control," International Conference on Intelligent Computation Technology and Automation, May 2010.

[17] G. Chen, "Conventional and Fuzzy PID Controllers: An Overview,” International Journal of Intelligent and Control Systems, vol. 1, no. 2, pp. 235-246, 1996.

[18] L. Luoh, “Control Design of T-S Fuzzy Large-Scale Systems,” International Journal of Innovative Computing, Information and Control, vol. 5, pp. 2869-2880, September 2009. 
[19] M. Wang, B. Chen, and S. Tong, “Adaptive Fuzzy Tracking Control for Strict-Feedback Nonlinear Systems With Unknown Time Delays,” International Journal of Innovative Computing, Information and Control, vol. 4, pp. 829-837, April 2008.

[20] R. Palm, “Robust Control by Fuzzy Sliding Mode,” Automatica, vol. 30, no. 9, pp. 1429-1437, September 1994.

[21] M. Short and F. Abugchem, "On the Jitter Sensitivity of an Adaptive Digital Controller: A Computational Simulation Study," International Journal of Engineering and Technology Innovation, vol. 9, no. 4, pp. 241-256, September 2019.

[22] J. L. Peczkowski and M. K. Sain, "Design of Nonlinear Multivariable Feedback Controls by Total Synthesis," American Control Conference, IEEE, July 1984, pp. 688-697.

[23] M. K. Sain and J. L. Peczkowski, "Nonlinear Multivariable Design by Total Synthesis,” American Control Conference, June 1982.

[24] J. L. Peczkowski and M. K. Sain, "Synthesis of System Responses: A Nonlinear Multivariable Control Design Approach," American Control Conference, June 1985.

[25] V. Aparna, M. Hussain K, D. N. Jamal, and M. S. M. Shajahan, "Implementation of Gain Scheduling Multiloop PI Controller Using Optimization Algorithms for a Dual Interacting Conical Tank Process,” 2nd International Conference on Trends in Electronics and Informatics, May 2018.

[26] X. Zhou, L. Li, Y. Jia, and T. Cai, “Adaptive Fuzzy/Proportion Integration Differentiation (PID) Compound Control for Unbalance Torque Disturbance Rejection of Aerial Inertially Stabilized Platform,” International Journal of Advanced Robotic Systems, vol. 13, no. 5, pp. 1-11, October 2016.

[27] C. Fuyan, Z. Guomin, L. Youshan, and X. Zhengming, "Fuzzy Control of a Double-Inverted Pendulum," Fuzzy Sets and Systems, vol. 79, no. 3, pp. 315-321, May 1996.

[28] S. R. Mahapatro, B. Subudhi, and S. Ghosh, “Adaptive Fuzzy PI Controller Design for Coupled Tank System: An Experimental Validation,” IFAC Proceedings Volumes, vol. 47, no. 1, pp. 878-881, 2014.

[29] S. R. Mahapatro, B. Subudhi, and S. Ghosh, "Design and Real-Time Implementation of an Adaptive Fuzzy Sliding Mode Controller for a Coupled Tank System," International Journal of Numerical Modelling: Electronic Networks, Devices and Fields, vol. 32, no. 1, p. e2485, September 2018.

[30] G. M. Tamilselvan and P. Aarthy, "Online Tuning of Fuzzy Logic Controller Using Kalman Algorithm for Conical Tank System,” Journal of Applied Research and Technology, vol. 15, no. 5, pp. 492-503, October 2017.

[31] G. Sakthivel, T. S. Anandhi, and S. P. Natarajan, "Design of Fuzzy Logic Controller for a Spherical Tank System and Its Real Time Implementation," International Journal of Engineering Research and Applications, vol. 1, no. 3, 2011.

[32] G. Stephanopoulos, "Chemical Process Control: An Introduction to Theory and Practice," Automatica, vol.21, no. 4, pp. 502-504, July 1985.

[33] J. M. Mendel, "Fuzzy Logic Systems for Engineering: A Tutorial," Proceedings of the IEEE, vol. 83, no. 3, pp. 345-377, March 1995.

[34] L. A. Zadeh, “Fuzzy Logic,” Computer, vol. 21, no. 4, pp. 83-93, April 1988.

Copyright $(\odot$ by the authors. Licensee TAETI, Taiwan. This article is an open access article distributed under the terms and conditions of the Creative Commons Attribution (CC BY-NC) license (https://creativecommons.org/licenses/by-nc/4.0/). 